\title{
STRATEGI PENGELOLAAN KAWASAN LINDUNG MANUCOCO BERBASIS MASYARAKAT DI KOTA ADMINISTRATIF ATAURO, DILI TIMOR-LESTE
}

\author{
Ernesto Matos Soares $\left.{ }^{1 *}\right)$, I Made Antara ${ }^{2}$ ), I Made Adhika ${ }^{3}$ ) \\ 1) Direktorat Jenderal Lingkungan Hidup Timor-Leste \\ 2) Fakultas Pertanian, Universitas Udayana \\ 3) Fakultas Teknik, Universitas Udayana \\ „) Email: ernestomatos.soares@yahoo.co.id
}

\begin{abstract}
Manucoco Protected Area is a mountainous conservation area which is very important for Atauro community because it functions as water catchment areas, especially water sources, important habitat for birds and other biodiversity, but there are still problems that occur such as deforestation, shifting cultivation, system of slash-and-burn cultivation, area zoning is not clear, the expansion of settlements and forest fires, all of these problems can give a less impact on ecological functions of the forest. The aims of this study are 1) to describe the perception of the public about the conservation of natural resources Manucoco Protected Area as a conservation area 2) to formulate management strategies for community-based Manucoco Protected Area. The data collection techniques used questionnaires, interviews, documentation, and focus group discussions, whereas the determination of the respondents used a purposive sampling method. To formulate a management strategy, internal and external factors were identified by using SWOT analysis. The results showed that the public perception of the function of the forest was that the forests had multiple functions, the public perception related to management policies showed that people did not know the forestry legislations. Public perception regarding the rights and obligations in the management strategy namely the public has the perception that forests are common property. Based on the SWOT analysis produced several communitybased management strategies that can be used in the management of Manucoco protected areas as follow 1) Maximizing the primary function of forests, (2) Increasing public knowledge through an intensive socialization (3) Increasing the involvement or participation of the community 4) Encouraging the community-based forests protection through HKM 5) Acceleration of area zoning 6) Increasing related department supervision 7) Performing the empowerment of communities around the protected areas 8) Preparing management plans which needs to involve all stakeholders 9) Establishing the management unit in the village/sub-district levels.
\end{abstract}

Keywords: Manucoco Protected Area, Pubic Perception, Conservation, Management Strategy

\section{PENDAHULUAN}

Kawasan lindung sebagai kawasan yang mempunyai manfaat untuk mengatur tata air, pengendalian iklim mikro, habitat kehidupan liar, sumber plasma nutfah serta fungsi sosial budaya bagi masyarakat di sekitarnya dengan demikian pengelolaan kawasan lindung harus betul-betul sesuai tingkat kepentinganya bagi suatu wilayah.

Pengelolaan hutan mempunyai peran penting untuk menunjang kelangsungan hidup semua mahluk hidup khususnya umat manusia, hutan tidak hanya memberikan manfaat langsung (tangible use) sebagai sumber penghasil hasil hutan berupa kayu dan non kayu, tetapi hutan juga memberikan manfaat tidak langsung (intangible use) sebagai pengatur tata air, kesuburan tanah, iklim mikro, pencegah erosi dan longsor, sehingga eksistensinya perlu tetap dipertahankan melalui pengaturan fungsi hutan, sehingga hutan diartikan sebagai asosiasi masyarakat tumbuh-tumbuhan dan hewan yang didominasi oleh pohon-pohonan dengan luasan tertentu sehingga dapat membentuk iklim mikro dan kondisi ekologi tertentu (Suparmoko,1997). Widada et al. (2006) bahwa hutan mempunyai beberapa fungsi diantaranya; mengatur tata air, mencegah dan membatasi banjir, erosi serta memelihara kesuburan tanah selain itu juga menyediakan hasil hutan untuk keperluan masyarakat, memberikan keindahan alam khususnya dalam bentuk cagar alam, suaka margasatwa,taman wisata, sebagai laboratorium untuk ilmu pengetahuan, pendidikan dan pariwisata fungsi lain juga sebagai salah satu unsur strategi pembangunan nasional.

Pengelolaan berbasis masyarakat merupakan suatu upaya pengelolaan yang dilakukan oleh masyarakat bersama-sama dengan pemerintah setempat, pengelolaan berbasis masyarakat 
bertujuan untuk melibatkan masyarakat secara aktif dalam kegiatan perencanaan dan pelaksanaan pengelolaan (Tulungen et al.2002).

Persepsi adalah pandangan atau penilaian seseorang terhadap obyek tertentu yang dihasilkan oleh kemampuan mengorganisasi pengamatan, persepsi sebagai proses pengorganisasian, penginterpretasian terhadap stimulus yang diterima oleh organism atau individu sehingga merupakan proses yang berarti dan merupakan proses integral dalam diri individu. Persepsi merupakan proses penginderaan dan penafsiran rangsangan suatu obyek atau peristiwa yang diinformasikan, sehingga seseorang dapat memandang, mengartikan dan menginterpretasikan rangsangan yang diterimanya sesuai dengan keadaan dirinya dan lingkungan dimana berada, sehingga dapat menentukan tindakannya Walgito (dalam Boedojo, 1986)

Wilayah hutan Timor-Leste \pm 869.130.41ha, mewakili $59 \%$ dari keseluruhan luas wilayah daratan 1.493.130.41 ha, kawasan hutan Timor-Leste diklasifikasi menjadi dua bagian yaitu hutan yang mempunyai tutupan bagus $312,930.67$ ha dan tutupan hutannya kurang 556.199.74 ha. (MAFP, 2004). Deforestasi disebabkan sistem curah hujan dan topografi di mana $41 \%$ dari total wilayah memiliki lereng lebih besar dari 40\% (Mota, 2002). TimorLeste memiliki 44 Kawasan Lindung yang telah ditetapkan berdasarkan Peraturan UNTAET No.19 tahun 2000.

Kawasan Lindung (KL) Manucoco merupakan kawasan konservasi pegunungan yang sangat penting bagi masyarakat Atauro karena mempunyai fungsi sebagai daerah resapan air terutama sumber mata air, habitat penting bagi burung dan keanekaragaman hayati lainnya, kawasan ini ditetapkan oleh Pemerintah Timor-Leste mengacu pada peraturan UNTAET No.19 tahun 2000, luas area KL Manucoco \pm 4000 ha, secara administratif KL Manucoco terletak di Kota Administatif Atauro dengan ketinggian 700-970 meter dpl. Keberadaan KL Manucoco sangat penting bagi Pulau Atauro yang kondisi geografinya kebanyakan berlereng terdapat sedikit dataran rendah di sekitar daerah pesisir, kondisi topografinya didominasi oleh bebatuan karang, curah hujannya pendek sehingga daerah ini adalah daerah kering, sehingga sangat penting untuk dikonservasi dan dilestarikan sebagai sumber penyedia sumber air bagi pulau tersebut karena kebanyakan sumber air bersih yang digunakan oleh masyarakat sumbernya dari KL Manucoco.

Belum adanya upaya pengelolaan terhadap kawasan lindung ini sehingga terjadi berbagai fenomena di antaranya kegiatan berladang masyarakat, pengambilan kayu bakar sebagai sumber energi bahan bakar dan penebangan pohon untuk kepentingan membuat rumah dan kapal tradisional/sampan, ladang berpindah, sistem bercocok tanam tebas dan bakar bertambahnya pemukiman penduduk dan kebakaran hutan semua permasalahan tersebut erat hubungannya dengan masyarakat yang tinggal di sekitar kawasan lindung. Keberhasilan pengelolaan kawasan konservasi perlu keterlibatan pemerintah secara aktif untuk mengajak dan merangkul masyarakat sekitar hutan untuk ikut menjaga keutuhan kawasan hutan dan memberikan pemahaman betapa pentingnya fungsi dan manfaat kawasan yang ada di sekitarnya, masyarakat tidak dilibat dalam suatu rencana pengelolaan maka masyarakat dihadapkan pada posisi yang dilematis dimana di satu sisi bertindak sebagai pelaku pembangunan dalam aktivitas kesehariannya untuk bertindak sebagai pelindung kelestarian hutan dan di sisi lain masyarakat juga turut serta berpartisipasi dalam perusakan, hal ini bisa di pengaruhi karena faktor ekonomi, sosial atau budaya yang melatarbelangi serta faktor pengetahuan yang minim.

Artikel ini membahas tentang dua hal pokok yang menjadi fokus pada penelitian ini yaitu 1) Bagaimana persespsi masyarakat tentang konservasi sumberdaya alam KL Manucoco, 2) Bagaimana strategi pengelolaan KL Manucoco sebagai kawasan konservasi berbasis masyarakat.

Penelitian ini dimaksudkan untuk merumuskan suatu strategi pengelolaan KL Manucoco berbasis masyarakat berdasarkan persepsi masyarakat sebagai acuan dan arahan untuk pengelolaan ke depan.

\section{METODOLOGI}

Penelitian ini dilakukan di KL (Kawasan Lindung) Manucoco Kota Administratif Atauro, terutama desa yang berdekatan dengan kawasan lindung seperti Desa Macadade, Desa Maquili, Desa Vila dan Desa Beloi, metode yang digunakan adalah metode penelitian kualitatif dan kuantitatif, data yang digunakan dalam penelitian ini adalah data primer dan data sekunder, untuk memperoleh data persepsi masyarakat mengunakan kuisioner/angket, analisis data mengunakan analisis deskriptif kualitatif, dalam merumuskan strategi pengelolaan mengunakan analisis SWOT berpedoman pada faktor internal dan eksternal, diskusi wawancara dan dokumentasi.

\section{HASIL DAN PEMBAHASAN}

\subsection{Keadaan Umum KL Manucoco}

KL Manucoco merupakan kawasan hutan konservasi yang berada di Kota Administratif Atauro Kota Madya Dili dengan luas 4000 hektar, meskipun sudah ditetapkan sebagai kawasan lindung kebijakan 
pemerintah untuk melakukan pengelolaan terhadap kawasan tersebut belum berjalan secara maksimal, secara keseluruhan masyarakat bersedia untuk mendukung kebijakan pemerintah dalam pengelolaan KL Manucoco. Potensi sumberdaya alam KL Manucoco seperti tanaman hias (bunga anggrek),rotan, pohon enau, bambu, kopi dan tanaman hutan lainnya seperti pohon kayu saria (Toona sureni), pohon kenari (Canarium reidentalia), ai na (Ptedocarpus indicus) dan berbagai jenis pohon lainnya, KL Manucoco sebagai habitat penting bagi burung, observasi peneliti terhadap aktivitas masyarakat dapat dilihat bahwa masyarakat dari desa yang ada di sekitar kawasan lindung banyak melakukan aktivitas perladangan untuk menanami jagung, kacang, ketela pohon, kelapa, pisang, nenas dan tanaman buah-buahan lainnya.

KL Manucoco memiliki berbagai fungsi yakni fungsi sosial, fungsi ekologis dan fungsi ekonomis, fungsi sosial hutan sebagai tempat wisata atau rekreasi, KL Manucoco menyimpan keindahan alam dan keanekaraman hayati baik flora maupun fauna yang bisa dikelola sebagai obyek wisata alam, fungsi ekologis berdasarkan pengamatan di lapangan terlihat bahwa masyarakat Atauro umumnya mengunakan mata air yang ada di KL Manucoco sebagai sumber air bersih, ada beberapa sumber mata air yang permanen atau sepanjang tahun tersedia yaitu di Desa Maquili terdapat Mata Air Tulai dan
Mata Air Ebua, sedangkan di Desa Macadade yaitu Mata Air di Kampung Berau, Mata Air Era Amak, Mata Air Essuan, Mata Air Era Apak, Mata Air Eralu dan Mata Air Asame Lolon pemanfatan sumber air yang ada untuk kepentingan masyarakat Kota Administratif Atauro untuk memenuhi kebutuhan sehari-hari baik untuk air minum, memasak maupun mandi. Fungsi ekonomis ialah hutan dapat menyediakan tanah yang subur dan hasil hutan yang bisa dimanfaatkan oleh masyarakat untuk mendapatkan uang untuk memenuhi kebutuhan hidup yaitu melakukan aktivitas sehari-hari dengan bertani di sekitar kawasan lindung, mencari kayu bakar dan menebang pohon yang besar untuk membuat perahu tradisional, pengalaman hidup sehari-hari masyarakat memberikan kontribusi terhadap timbulnya persepsi bahwa hutan memiliki fungsi ekonomi.

\subsection{Persepsi Masyarakat Mengenai KL Manucoco Sebagai Kawasan Konservasi}

Berdasarkan data persepsi masyarakat mengenai pelestarian KL sebagai kawasan konservasi terbagi dalam tiga bagian, diantaranya persepsi masyarakat mengenai fungsi KL Manucoco, persepsi masyarakat tentang kebijakan pengelolaan, persepsi masyarakat tentang hak dan kewajiban masyarakat dalam pengelolaan.

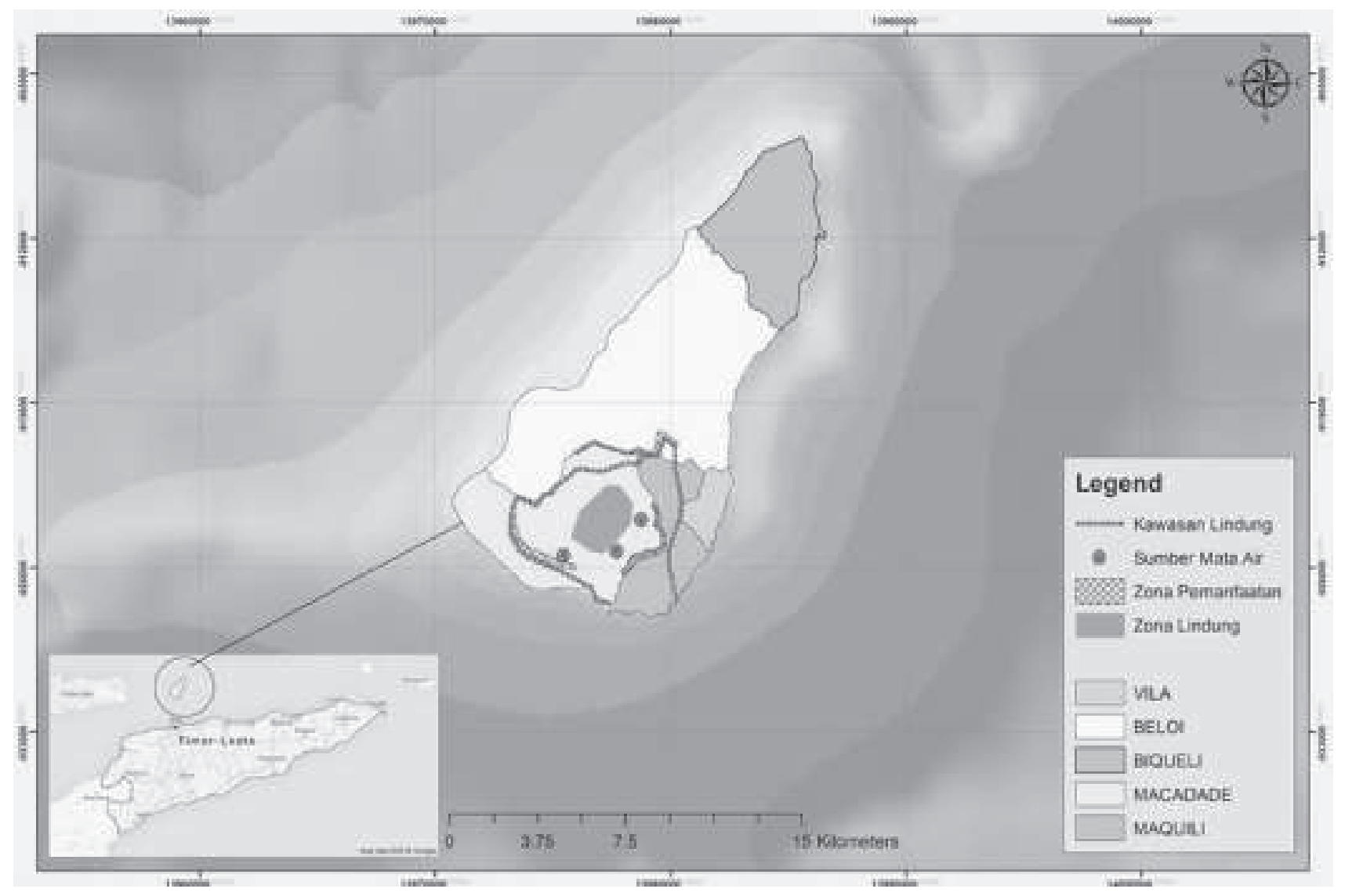

Gambar 3.1 Peta Lokasi Penelitian 


\subsubsection{Persepsi Masyarakat Mengenai Fungsi Hutan KL Manucoco}

A. Persepsi masyarakat mengenai fungsi hutan Persepsi masyarakat mengenai fungsi hutan, dianalisis bahwa hutan merupakan salah satu komponen penting sumberdaya alam yang mempunyai fungsi majemuk yaitu memiliki fungsi sosial (sebagai tempat rekreasi/berlibur), fungsi ekologis (seperti menyimpan cadangan air, mencegah banjir/erosi dan sebagai tempat hidup fauna serta keanekaragaman hayati lainya) dan fungsi ekonomi (untuk mencari penghasilan), persepsi tersebut ditunjukan dengan $60 \%$ respon den mempersepsikan bahwa hutan memiliki banyak fungsi (majemuk) sedangkan $40 \%$ mempersepsikan bahwa hutan memilki fungsi tunggal.

B. Persepsi masyarakat mengenai fungsi sumberdaya alam KL Manucoco

Pada umumnya masyarakat yang mempersepsikan fungsi hutan yang masih baik ditandai dengan adanya kerapatan vegetasi, aktivitas masyarakat yang rendah di dalam kawasan adanya pemanfaatan jasa lingkungan serta ketersediaan sumber mata air, masyarakat yang mempersepsikan fungsi hutan masih baik mengindikasikan bahwa secara sadar maupun tidak masyarakat akan mengamati kondisi hutan seperti luas hutan dan jumlah penduduk yang tinggal di kawasan hutan meskipun masyarakat tidak secara spesifik menyebutkan angka kuantitatif luas hutan dan jumlah penduduk yang tinggal di kawasan hutan, persepsi masyarakat dibuktikan dengan $66,67 \%$ responden menyatakan bahwa KL Manucoco masih berfungsi dengan baik sebagai kawasan konservasi, $17,78 \%$ menyatakan tidak berfungsi dengan baik dan 15,55 menyatakan tidak tahu, masyarakat yang mengatakan bahwa kondisi hutan masih baik tidak selalu bermakna fungsinya masih baik, melainkan dapat bermakna bahwa masyarakat setempat masih dapat menggantungkan kehidupan sosial ekonominya akibat keberadaan hutan.

C. Persepsi masyarakat mengenai pengaruh KL Manucoco terhadap kehidupan masyarakat

Berdasarkan hasil tabulasi terhadap persepsi masyarakat menunjukkan bahwa 53,33\% menyatakan KL Manucoco berpengaruh terhadap kehidup masayarakat, $20 \%$ menyatakan tidak berpengaruh dan $26,67 \%$ tidak tahu, hasil tersebut menunjukkan bahwa adanya interaksi masyarakat terhadap kawasan hutan meningkat atau kemungkinan masyarakat umumnya berprofesi sebagai petani sehingga mau tidak mau harus melakukan aktivitas bertani di sekitar kawasan hutan sebagai sumber kehidupannya baik ekonomi maupun sosial, sadar atau tidak meningkatnya tingkat ketergantungan pada hutan akan berpengaruh terhadap fungsi kawasan dan luasan hutan.

\subsubsection{Persepsi Masyarakat Tentang Kebijakan Pengelolaan}

A. Pengetahuan masyarakat mengenai peraturan perundanagan

Berdasarkan hasil tabulasi pengetahuan masyarakat tentang peraturan perundangan menunjukkan bahwa $68,88 \%$ tidak mengetahui tentang peraturan perundanagan kehutanandan $31,11 \%$ tahu, kondisi ini mungkin disebabkan karena saat ini Timor-Leste belum memiliki UU Kehutanan dan minimnya frekuensi sosialisasi.

B. Persepsi masyarakat mengenai kelembagaan pengelolaan hutan.

Masyarakat punya persepsi bahwa lembaga pengelola harus ditandai dengan adanya bangunan fisik seperti tersedia kantor untuk aktivitas para pengelola, persepsi tersebut dibuktikan dengan $71,11 \%$ responden menyatakan bahwa KL Manucoco belum mempunyai lembaga pengelola, $6.67 \%$ menyatakan ada dan $22,22 \%$ tidak tahu, berdasarkan hasil tersebut secara tidak sadar masyarakat sudah mempersepsikan bahwa hutan perlu dikelola. Belum adanya lembaga pengelola secara psikologis terkait dengan stimulan persepsi yang tumbuh di masyarakat bahwa hutan merupakan teritori yang bebas dan bisa di manfaatkan untuk kegiatan apa saja secara bebas atau sembarangan oleh masyarakat.

C. Persepsi masyarakat mengenai Pengelolaan hutan membutuhkan rencana

Persepsi masyarakat mengenai perlu adanya rencana dalam pengelolaan hutan maka baik responden yang menjawab tahu tentang UndangUndang Kehutanan maupun yang tidak tahu, semuanya menjawab bahwa dalam pengelolaan hutan memerlukan rencana, hal ini dibuktikan dengan 55,56\% menjawab bahwa perlu adanya rencana dalam pengelolaan sumberdaya hutan, $35,55 \%$ tidak membutuhkan rencana, 8,89\% tidak tahu, hasil ini menunjukkan masyarakat mempersepsikan kebijakan sebagai sesuatu yang sifatnya diberikan (given) dari pemerintah sebagai pembuatan kebijakan tanpa diketahui masyarakat dari mana asal kebijakan itu

D. Persepsi masyarakat mengenai peran serta dalam pengelolaan KL Manucoco

Kebijakan yang diterapkan dengan tujuan untuk meningkatkan kesejahteraan masyarakat sehingga masyarakat menyadari bahwa kebijakan sebagai sesuatu yang familiar bagi masyarakat, berdasarkan 
jawaban responden bahwa perlu peran serta masyarakat dalam pengelolaan hutan, yaitu sebanyak 64,44\% responden berpendapat bahwa masyarakat perlu dilibatkan dalam proses pengelolaan hutan, tidak perlu $20 \%$ dan $15,56 \%$ tidak tahu, hasil ini menunjukkan bahwa tidak ada pelibatan masyarakat akan berdampak terhadap tidak adanya rasa memiliki dan peran sertanya dalam pelestarian hutan sedangkan masyarakat yang dilibatkan dalam pengelolaan hutan tentu rasa memiliki relatif lebih tinggi dibandingkan masyarakat yang tidak dilibatkan.

E. Persepsi masyarakat mengenai bentuk pelibatan yang diinginkan dalam pengelolaan

Kebijakan pengelolaan hutan yang diterapkan harus menyentuh aspek mendasar kehidupan masyarakat yakni aspek ekonomi, pelibatan dalam kerangka pemenuhan kesejahteraan masyarakat sebenarnya secara otomatis dapat menjamin bahwa masyarakat memiliki rasa tanggungjawab untuk menjaga kelestarian hutan sebagai sumber penghidupannya Persepsi masyarakat mengenai bentuk pelibatan menunjukkan $57,78 \%$ responden ingin untuk berpatisipasi dalam pengelolaan (pola pengelolaan partisipatif) sehingga dapat memperoleh manfaat ekonomi, turut mengawasi pengelolaan hutan supaya tidak disalahgunakan. Bentuk pelibatan yang diinginkan tersebut berarti masyarakat tidak ingin sekedar dilibatkan dalam pengelolaan hutan dalam bentuk mengawasi kelestarian hutan, melainkan melalui keterlibatan akan mendapatkan manfaat ekonomi, keterlibatan tersebut berhubungan dengan tingkat sosial ekonomi masyarakat yang tinggal di kawasan hutan, artinya jika ada masyarakat yang tinggal di kawasan hutan maka kepentingan ekonominya harus diperhatikan.

\section{F. Persepsi masyarakat mengenai Penyuluhan/ sosialisasi instansi terkait}

Penyuluhan merupakan faktor yang penting dan sebagai salah satu bentuk tindakan dalam rangka implementasi kebijakan pengelolaan dan pelestarian hutan, terkait dengan penyuluhan maka 48,88\% responden menjawab bahwa penyuluhan pernah dilakukan dan tidak pernah $26,67 \%$ dan tidak tahu $24,44 \%$, Jawaban ini menunjukkan bahwa tidak meratanya sosialisasi yang dilakukan instansi terkait kepada masyarakat, program penyuluhan yang dilakukan hanya sebagai mengejar target program semata tanpa mengedepan manfaat dari program tersebut.

\subsubsection{Persepsi Masyarakat mengenai Hak dan Kewajiban dalam Pengelolaan}

A. Persepsi masyarakat mengenai hak dan kewajiban dalam pengelolaan

Berdasarkan analisis persepsi masyarakat mengenai hak dan kewajiban dalam pengelolaan hutan merupakan satu paket kegiatan yang tidak dapat dipisahkan satu dan lainnya dalam rangka memenuhi rasa keadilan publik (public justice) artinya bahwa pemenuhan kewajiban oleh masyarakat harus disertai adanya jaminan bahwa haknya juga dipenuhi, sesuai dengan hasil analisis diketahui bahwa masyarakat tidak memiliki pengetahuan yang memadai tentang peraturan perundangan kehutanan, jawaban ini dibuktikan dengan $62,22 \%$ responden tidak mengetahui hak dan kewajiban dalam pengelolaan hutan dalam konteks hukum yang ada.

\section{B. Persepsi masyarakat mengenai tindakan konservasi}

Masyarakat memiliki persepsi bahwa tindakan konservasi itu perlu karena di dalam tindakan konservasi tersebut masyarakat memiliki kepentingan sosial ekonomi,tindakan konservasi hutan sebenarnya dalam pengertian bahwa konservasi tersebut mensyaratkan adanya periode penanaman dan penebangan hutan, masyarakat mempersepsikan bahwa jika sudah menanam dan merawat tanaman/pohon di hutan, terlepas dari jenisnya, periode penanaman dan pemanenan hasil, maka menurut masyarakat hal itu berarti sudah ikut berpartispasi dalam konservasi hutan, masyarakat berpendapat bahwa konservasi tersebut menguntungkan karena bisa memenuhi kebutuhan ekonominya, persepsi ini dibuktikan dengan 88,89\% responden menjawab bahwa tindakan konservasi menguntungkan dan $11,11 \%$ tidak tahu.

C. Persepsi masyarakat mengenai aktivitas mengubah fungsi pokok KL Manucoco

Terlepas dari pengetahuan masyarakat tentang fungsi pokok hutan masyarakat memiliki persepsi bahwa di kawasan hutan dimana mereka berdomisili cenderung tidak ada aktivitas yang merubah fungsi pokok hutan, persepsi ini dibuktikan dengan jawaban responden $46,67 \%$ ada aktivitas mengubah fungsi KL Manucoco, tidak ada $42,22 \%$ dan tidak tahu $11,11 \%$, hasil ini menunjukkan bahwa berubahnya fungsi pokok hutan salah satunya disebabkan oleh tekanan kebutuhan akan perumahan seiring dengan pertumbuhan penduduk dan aktivitas budidaya. 
Tabel 3.1. Identifikasi Faktor Internal dan Faktor Eksternal

\begin{tabular}{|c|c|}
\hline Faktor Internal & Faktor Eksternal \\
\hline Faktor Kekuatan (Strength) & Faktor peluang (Opportunitties) \\
\hline 1. KL Manucoco sebagai kawasan konservasi & 1. Adanya dukungan pemerintah lokal dalam upaya konservasi \\
\hline $\begin{array}{l}\text { 2. Keinginan masyarakat untuk turut serta dalam pengelolaan } \\
\text { hutan } \mathrm{KL} \text { Manucoco }\end{array}$ & $\begin{array}{l}\text { 2. Masyarakat mendukung untuk berpartisipasi dalam pelestarian kawasan } \\
\text { lindung Manucoco }\end{array}$ \\
\hline 3. Sebagai daerah resapan air dan daerah penting bagi burung & 3. Status sebagai kawasan lindung \\
\hline 4. Adanya kearifan lokal tarabandu untuk pelestarian hutan & \\
\hline 5. Kondisi hutan primer masih baik & \\
\hline Faktor Kelemahan (weaknesses) & Faktor Ancaman (Threats) \\
\hline $\begin{array}{l}\text { 1. Pengetahuan masyarakat tentang peraturan perundangan } \\
\text { kehutanan masih minim }\end{array}$ & $\begin{array}{l}\text { 1. Penebangan pohon } \\
\text { 2. Lahan berpindah }\end{array}$ \\
\hline 2. Kurangnya keterlibatan/swadaya masyarakat dalam pelestarian hutan & 3. Adanya pemukiman warga masuk ke dalam kawasan hutan \\
\hline 3. Penataan kawasan belum jelas & 4. Kebakaran hutan \\
\hline 4. Minimnya petugas kehutanan dalam pengawasan & \\
\hline 5. Kurangnya pemberdayaan masyarakat. & \\
\hline 6. Rendanya intensitas sosialisasi & \\
\hline 7. Lemahnya penegakan hukum & \\
\hline 8. Tidak ada unit/lembaga pengelola & \\
\hline
\end{tabular}

Tabel 3.2. Matriks Formulasi SWOT Strategi Pengelolaan KL Manucoco

\begin{tabular}{|c|c|c|}
\hline & Strengths (S) & Weaknesses (W) \\
\hline Faktor Eksteral & $\begin{array}{l}\text { 1. Berfungsi sebagai area } \\
\text { konservasi } \\
\text { 2. Keinginan masyarakat untuk } \\
\text { turut serta dalam pelestarian } \\
\text { hutan } \\
\text { 3. Sebagai daerah resapan air } \\
\text { dan daerah penting burung } \\
\text { 4. Kondisi hutan primer masih } \\
\text { baik } \\
\text { 5. Adanya kearifan lokal } \\
\text { tarabandu dalam menjaga } \\
\text { kelestarian hutan }\end{array}$ & $\begin{array}{l}\text { 1. Pengetahuan masyarakat tentang } \\
\text { peraturan perundangan Kehutanan } \\
\text { masih kurang } \\
\text { 2. Minimnya SDM petugas } \\
\text { kehutanan dalam pengawasan } \\
\text { 3. Kurangnya keterlibatan /swadaya } \\
\text { masyarakat dalam pelestarian hutan } \\
\text { 4. Kurangnya pemberdayaan } \\
\text { masyarakat di sekitar kawasan hutan } \\
\text { 5. Penataan kawasan belum jelas } \\
\text { 6. Rendahnya intensitas sosialisasi \& pelestarian } \\
\text { hutan } \\
\text { 7. Lemahnya penegakan hukum } \\
\text { 8. Belum ada unit/lembaga pengelola }\end{array}$ \\
\hline Opportunities (O) & Strategi SO & Strategi WO \\
\hline $\begin{array}{l}\text { 1. Adanya dukungan pemerintah lokal } \\
\text { setempat } \\
\text { 2. Masyarakat mendukung untuk } \\
\text { berpartisipasi dalam pelestarian } \\
\text { kawasan lindung Manucoco } \\
\text { 3. Statusnya sebagai } \\
\text { kawasan lindung }\end{array}$ & $\begin{array}{l}\text { 1. Menerapkan aturan } \\
\text { pengelolaan disesuaikan } \\
\text { dengan kondisi kawasan } \\
(\mathrm{S} 1, \mathrm{~S} 3, \mathrm{~S} 5,01,02, \mathrm{O}) \\
\\
\text { 2. Memaksimalkan } \\
\text { fungsi utama hutan } \\
(\mathrm{S} 1, \mathrm{~S} 3, \mathrm{~S} 4,02, \mathrm{O},)\end{array}$ & $\begin{array}{l}\text { 1. Meningkatkan penyuluhan dan } \\
\text { keterlibatan/peran serta masyarakat } \\
\text { dalam pelestarian hutan } \\
(\mathrm{O} 2, \mathrm{O} 3, \mathrm{~W} 3, \mathrm{~W} 4, \mathrm{~W} 5, \mathrm{~W} 7, \mathrm{~W} 8) \\
\text { 2. Meningkatkan Pemberdayaan masyarakat } \\
\text { sekitar kawasan } \\
\text { hutan } \\
(\mathrm{O} 1, \mathrm{O} 3, \mathrm{~W} 1, \mathrm{~W} 3, \mathrm{~W} 4) \\
\text { 3. Membuat Penataan kawasan } \\
(\mathrm{O} 2, \mathrm{O} 3, \mathrm{~W} 2, \mathrm{~W} 5)\end{array}$ \\
\hline $\begin{array}{l}\text { Threats (T) } \\
\text { 1. Penebangan pohon dan kebakaran } \\
\text { hutan } \\
\text { 2. Lahan berpindah } \\
\text { 3. Adanya pemukimaan warga masuk ke }\end{array}$ & $\begin{array}{l}\text { Strategi ST } \\
\text { 1. Menerapkan pola } \\
\text { Perlindungan dan } \\
\text { pengamanan hutan berbasis } \\
\text { masyarakat }\end{array}$ & $\begin{array}{l}\text { Strategi WT } \\
\text { 1. Meningkatkan pengawasan terhadap } \\
\text { pengelolaan Sumberdaya hutan } \\
(W 1, W 2, W 8, T 1, T 2, T 3, T 4) \\
\text { 2. Penyusunan rencana kebijakan pengelolaan } \\
\text { perlu melibatkan semua pemangku }\end{array}$ \\
\hline $\begin{array}{l}\text { dalam kawasantimdung } \\
\text { 4. Kebakaran hutan }\end{array}$ & $(\mathrm{S} 3, \mathrm{~S} 4, \mathrm{~S} 5, \mathrm{~T} 1, \mathrm{~T} 2, \mathrm{~T} 3, \mathrm{~T} 4)$ & $\begin{array}{l}\text { kepentingan } \\
\text { (W2,W3,T2,T3) }\end{array}$ \\
\hline
\end{tabular}


D. Persepsi Masyarakat Mengenai Kearifan Lingkungan

Kearifan lingkungan atau kearifan lokal (local wisdom) merupakan suatu kebiasaan tradisional yang ada pada suatu daerah yang dipercaya dapat berkontribusi dalam menjaga atau melestarikan SDA yang ada pada suatu daerah, menurut informasi yang dapat di lapangan bahwa dalam upaya untuk menjaga kelestarian SDA bahwa telah dilakukan aktivitas upacara ritual tara bandu yang diselengarakan yang diprakarsa oleh tokoh adat setempat dengan bantuan dari pemerintah yaitu sebagai upaya melarang masyarakat agar tidak merusak sumberdaya alam, hal yang dipantangkan seperti dilarang membakar hutan, jangan sembarang menebang pohon di sumber mata air dan lain-lain, apa bila melanggar atau kedapatan maka akan dikenakan sanksi, persepsi ini dibuktikan dengan 84,44\% menyatakan ada kearifan lingkungan untuk menjaga kelestarian SDA KL Manucoco.

\subsection{Strategi Pengelolaan KL Manucoco Sebagai Kawasan Konservasi}

\subsubsection{Identifikasi Faktor Internal dan Eksternal}

Penyusunan strategi pengelolaan sumberdaya hutan KL Manucoco diawali dengan pengumpulan data faktor internal (Kekuatan dan Kelemahan) dan faktor eksternal (Peluang dan Ancaman) untuk merumuskan strategi-strategi pengelolaan, seperti disajikan pada Tabel 3.1

\subsubsection{Strategi Pengelolaan KL Manucoco Sebagai Kawasan Konservasi}

Berpedoman pada hasil observasi lapangan jawaban responden diskusi dan wawancara maka terindentifakasi faktor internal (kekuatan dan kelemahan) dan eksternal (peluang dan ancaman) yang mempengaruhi pengelolaan KL Manucoco kemudian dianalisis untuk merumuskan strategi pengelolaan sumberdaya alam KL Manucoco sebagai kawasan konservasi seperti pada Tabel 3.2

\section{SIMPULAN DAN SARAN}

\subsection{Simpulan}

Berdasarkan hasil dan pembahasan maka dapat dirumuskan beberapa simpulan sebagai berikut:

1. Persepsi masyarakat terhadap pelestarian sumberdaya alam KL Manucoco sebagai kawasan konservasi antara lain:

a) Persepsi masyarakat mengenai fungsi hutan bahwa hutan memiliki beraneka ragam fungsi (majemuk) yaitu fungsi ekologis, fungsi sosial dan fungsi ekonomi. b) Persepsi masyarakat mengenai kebijakan pengelolaan pada umumnya masyarakat tidak mengetahui peraturan atau regulasi yang mengatur tentang kehutanan, sehingga masyarakat tidak mempunyai pola berfikir mengenai tindakan pengelolaan dan pelestarian hutan

c) Persepsi masyarakat mengenai hak dan kewajiban dalam pengelolaan sumberdaya alam ialah masyarakat beranggapan bahwa hutan merupakan barang publik (common property) sehingga masyarakat merasa punya hak dan kewajiban untuk berpartisipasi untuk menjaga dan memelihara kelestarian sumberdaya alam yang ada, selain itu masyarakat mempersepsikan bahwa kearifan lokal/ aturan adat sangat bermanfaat dalam upaya pelestarian sumberdaya alam.

2. Strategi Pengelolaan KL Manucoco Berbasis Masyarakat yang perlu dilakukan yaitu: (1) memaksimalkan fungsi utama hutan (2) meningkatkan program sosialisai secara intensif (3) Menerapkan pola perlindungan dan pengamanan hutan berbasis masyarakat (4) meningkatkan keterlibatan atau peran serta masyarakat dan instansi terkait dalam upaya konservasi terhadap KL Manucoco (5) percepatan penataan kawasan (6) meningkatkan pengawasan terhadap pelestarian hutan (7) meningkatkan pemberdayaan terhadap masyarakat sekitar kawasan lindung melalui HKM (8) penyusunan rencana/kebijakan pengelolaan bersama perlu melibatkan semua komponen masyarakat (stakeholder) (9) pembentukan unit pengelola tingkat desa atau kecamatan.

\subsection{Saran}

Berdasarkan pembahasan maka dapat disarankan beberapa hal yang perlu dilakukan dalam pengelolaan KL Manucoco sebagai berikut:

1) Para pemangku kepentingan (stakeholder) diharapkan untuk menerapkan strategi-strategi yang hasilkan dalam penelitian ini sebagai acuan untuk pengelolaan KL Manucoco ke depan

2) Pemerintah perlu merampungkan proses pembuatan Peraturan PerundanganKehutanan sebagai payung hukum untuk mengatur tata kelola Kehutanan di Timor-Leste dan khususnya KL Manucoco

3) Perlu membentuk unit pengelola tingkat desa atau kecamatan (UPTD/UPTK) untuk melakukan pengelolaan atau pelestarian terhadap KL Manucoco 
4) Perlu dilakukan sosialisasi secara intensif serta meningkatkan pemberdayaan terhadap masyarakat yang tinggal di sekitar kawasan lindung

5) Bagi masyarakat Atauro perlu menghidupkan nilai kebersamaan untuk mempertahankan KL Manucoco sebagai aset penting melalui program konservasi secara swadaya untuk tetap menjaga fungsi ekologis hutan

\section{DAFTAR PUSTAKA}

Boedojo.1986. Arsitektur, Manusia dan Pengamatannya. Jakarta: Djambatan

Hadi, P.2005. Dimensi Lingkungan Perencanaan Pembangunan. Gadjah Mada University Press, Yogyakarta.

Mota,F. (2002). Timor Leste: As novas Florestas do Pais.Ministério da Agricultura e Pescas, Direcção Geral de Agricultura, Divisão de Florestas.
Suparmoko,1997. Ekonomi Sumberdaya Alam dan Lingkungan, BPFE: Yogyakarta

Tulungen J. Bayer. T, Dimpudus. M, Kasmidi. M, Rotinsulu. C, Sukmara. A,

Tangkilisan N. (2002). Panduan Pembentukan dan Pengelolaan Daerah Perlindungan Laut Berbasis Masyarakat. Departemen Kelautan dan Perikanan Jakarta

Peraturan UNTAET No. 19/2000 Tentang Penetapan Zona Kawasan Lindung Timor-Leste

Widada, Sri Mulyati, Hirishi Kobayashi, (2006). Sekilas Tentang Konservasi Sumberdaya Alam Hayati dan Ekosistemnya, Jakarta: Pt. Penebar Swadaya 